\title{
The effect of different lipid emulsions on appetite and energy intake
}

\author{
C. J. Harden ${ }^{1}$, M. E. Barker ${ }^{1}$, J. M. Russell ${ }^{2}$, S. F. Plummer ${ }^{3}$ and B. M. Corfe ${ }^{1}$ \\ ${ }^{1}$ Molecular Gastroenterology Research Group, Academic Unit of Surgical Oncology, Department of Oncology, \\ School of Medicine and Biomedical Sciences, The University of Sheffield, Sheffield, S10 2RX, ${ }^{2}$ Corporate Information \\ and Computing Services, The University of Sheffield, Sheffield, UK, S10 2RX and ${ }^{3}$ Cultech Ltd., Unit 3, Christchurch Road, \\ Port Talbot, West Glamorgan, SA12 7BZ, UK
}

Research examining the effects of different fatty acids on appetite is limited, but suggests that longer-chain polyunsaturated fatty acids may have greater appetite suppressing effects than shorter-chain, mono- and saturated fatty acids ${ }^{(1,2)}$.

An acute, double-blinded, randomised, controlled crossover study was conducted to examine the effects of isocaloric- orosensorymatched $45 \%$ oil-in-water emulsions containing predominantly docosahexaenoic acid (DHA) oleic acid (OA) or a blend of oils that reflect the Western diet (WB) compared to no treatment (NT) on subjective appetite scores and energy intake. On day one, subjects commenced three-day estimated household measures diet diaries and consumed a standardised, fixed-load evening meal followed by a fast until a standardised breakfast the following day. On day two, subjects completed visual analogue appetite questionnaires ${ }^{(3)}$ at 08:40, 09:00, 09:30, 09:45, 10:00, 10:30, 11:00, 11:30 and 12:00 hr. They consumed NT or $6 \mathrm{~mL}$ emulsion at 08:45 hr and then a fixed-load, low-fat breakfast at $09: 05 \mathrm{hr}$.

There was a significant effect of treatment on appetite scores. 'Hunger' was greater after WB compared to DHA and OA and after NT compared to DHA. 'Fullness' was lower after WB compared to DHA and OA. 'Prospective consumption' (how much do you think you can eat) was higher and 'satisfaction' was lower after WB compared to DHA (all $p<0.05)$. Critically, the direction of change for WB opposed the effects of the other treatments and NT, suggesting an appetitive effect of WB. There was no effect of treatment on energy intake at first post-intervention eating occasion or for the total day two (Table 1) questioning the value of appetite rating as a proxy marker of energy intake or behaviour.

Table 1. Between treatment differences in subjective appetite scores and energy intake

\begin{tabular}{|c|c|c|c|c|c|c|c|c|c|}
\hline \multirow[b]{3}{*}{ Appetite parameter } & \multicolumn{9}{|c|}{ Treatment } \\
\hline & \multicolumn{2}{|c|}{ NT } & \multicolumn{2}{|c|}{$\mathrm{OA}$} & \multicolumn{2}{|c|}{ DHA } & \multicolumn{2}{|c|}{ WB } & \multirow[t]{2}{*}{$p=$} \\
\hline & Mean & $\overline{\mathrm{SD}}$ & Mean & $\overline{\mathrm{SD}}$ & Mean & $\overline{\mathrm{SD}}$ & Mean & $\overline{\mathrm{SD}}$ & \\
\hline AUC Hunger & $-112^{\mathrm{a}}$ & 156 & $-194^{\mathrm{c}}$ & 160 & $-233^{a, b}$ & 155 & $68^{\mathrm{b}, \mathrm{c}}$ & 259 & $\overline{0.001}$ \\
\hline AUC Satisfaction & 138 & 121 & 190 & 171 & $228^{\mathrm{a}}$ & 146 & $-33^{\mathrm{a}}$ & 320 & 0.010 \\
\hline AUC Fullness & 150 & 145 & $210^{\mathrm{a}}$ & 161 & $222^{\mathrm{b}}$ & 141 & $-80^{\mathrm{a}, \mathrm{b}}$ & 287 & 0.005 \\
\hline AUC PC & -96 & 177 & -162 & 129 & $-173^{a}$ & 159 & $44^{\mathrm{a}}$ & 271 & 0.013 \\
\hline EI at first EO (kcal) & 613 & 224 & 688 & 341 & 508 & 248 & 555 & 266 & 0.156 \\
\hline Total EI (kcal) day 2 & 2352 & 666 & 2470 & 630 & 2370 & 661 & 2306 & 743 & 0.922 \\
\hline
\end{tabular}

$\mathrm{AUC}=$ area under the curve, $\mathrm{PC}=$ prospective consumption, $\mathrm{EI}=$ energy intake, $\mathrm{EO}=$ eating occasion.

Those in the same row sharing the same letter are significantly different at $p<0.05$.

Despite significant between-treatment differences in subjective appetite scores, the lipid preloads did not alter energy intake. These discrepancies may be because lifestyle and factors such as schedule, money and food availability were the primary contributors of energy intake and physiological appetite sensations were overridden. Other researcher report that subjective appetite scores are not useful predictors of energy intake ${ }^{4}$.

1. Lawton CL, Delargy HJ, Brockman J et al. (2000) Br J Nutr 83, 473-482.

2. Feltrin KL, Little TJ, Meyer JH et al. (2004) Am J Physiol Regul Integr Comp Physiol 287, 524-533.

3. Flint A, Raben A, Blundell JE et al. (2000) Int J Obes 24, 38-48.

4. Maljaars J, Romeyn EA, Haddeman E et al. (2009) Am J Clin Nutr 89, 1019-24. 